https://cssr.uitm.edu.my/2018/

5th International Conference on Science and Social Research

Le Meridien Kota Kinabalu Hotel, 5 - 6 December 2018

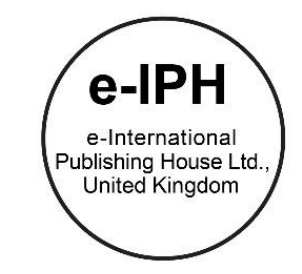

\title{
Degree of 5-Reaches in Teaching of Control System Design
}

\author{
Khuan Y. Lee \\ Faculty of Electrical Engineering, Universiti Teknologi MARA, 40450 Shah Alam, Malaysia \\ Computational Intelligence EK, Pharmaceutical and Lifesciences Communities of Research, \\ Universiti Teknologi MARA, 40450 Shah Alam, Malaysia \\ leeyootkhuan@uitm.edu.my \\ Tel: +60122011760
}

\begin{abstract}
Control System Design course prepares students to design automatic systems, which is indispensable of the engineering curriculum. This paper intends to illustrate how the effective learning techniques of Lu Xun are adapted as activities in the teaching of the course. This is the first time that the content design and delivery of the course are analysed objectively. From a study population of 128 students, Activity 5-9 are found to be the most capable of engaging the students to use the 5-organs while learning the course. And the Eye, Hand and Brain are the most engaging organs.
\end{abstract}

Keywords: Lu Xun; 5-reaches; Control System Design

eISSN: 2398-4287@ 2020. The Authors. Published for AMER ABRA cE-Bs by e-International Publishing House, Ltd., UK. This is an open access article under the CC BYNC-ND license (http://creativecommons.org/licenses/by-nc-nd/4.0/). Peer-review under responsibility of AMER (Association of Malaysian Environment-Behaviour Researchers), ABRA (Association of Behavioural Researchers on Asians) and cE-Bs (Centre for Environment-Behaviour Studies), Faculty of Architecture, Planning \& Surveying, Universiti Teknologi MARA, Malaysia. DOI: https://doi.org/10.21834/ebpj.v5iSI3.2561

\subsection{Introduction}

The two most acclaimed figures of Classical Chinese poetry during the Tang Dynasty, or the Golden Age of China: Li Bai (701 - 762), the God of Classical Chinese Poetry, is said never let a book of his hand; Du Fu (712-770), the Master of Classical Chinese Poetry, has his famous saying, "Read widely and you will write wisely". The God of Modern Chinese literature, Lu Xun, is said to have read till his last breath. Karl Marx, who founded Marxism, admitted being a book worm himself. Napoleon Bonaparte, one of the greatest commanders in history, whose strategies are still being studied at military schools worldwide, attributed his success in politics and military to inexhaustible reading. Self-made entrepreneur Lee Ka Shing cultivates an insatiable appetite for reading and learning. To him, reading is the key to success. He reads on history, technology, philosophy, trade journals, business books and anything related to the industries involved (Li., 2014). From just a handful of them, it can be observed that all these prominent global figures share a common trait, i.e. passion in reading. Their avid and prolific reading experience must have induced an effective learning style in them that assimilates information from reading into knowledge and practice that help them succeed in their undertakings. Amongst them, Lu Xun 5-Reaches learning technique which promotes simultaneous engagement of 5-organs has now been popularly advocated by primary schools, secondary schools, universities and even governments of China.

Control system integrates a multi-disciplinary field of knowledge for regulating a process to its desired performance. In its basic configuration for automation, for the reason of safety, inaccessibility, productivity or quality, it requires modelling (chemical, physical, mechanical, electrical, fluidic etc.), sensing technology ( $\mathrm{pH}$, ionic, temperature, wavelength, position, velocity, current etc.), control algorithm (gain, PI/Lag, PD/Lead, PID/Lead-Lag etc.) and actuating technology (pump, valve, motor etc.). Control System Design

eISSN: 2398-4287@ 2020. The Authors. Published for AMER ABRA cE-Bsby e-International Publishing House, Ltd., UK. This is an open access article under the CC BYNC-ND license (http://creativecommons.org/licenses/by-nc-nd/4.0/). Peer-review under responsibility of AMER (Association of Malaysian Environment-Behaviour Researchers), ABRA (Association of Behavioural Researchers on Asians) and cE-Bs (Centre for Environment-Behaviour Studies), Faculty of Architecture, Planning \& Surveying, Universiti Teknologi MARA, Malaysia.

DOI: https://doi.org/10.21834/ebpj.v5iSI3.2561 
course prepares students to design these automatic control systems, in time and frequency domain, for applications in the many disciplines. It is indispensable in the most engineering curriculum, in particular electrical, chemical and mechanical. Despite its exciting practical applications, ranging from control of the engineering system as big as a hydroelectric turbine to that as minute as micro-drug delivery robots, the course poses a threat amongst students. It is highly mathematical, besides requiring analytical, synthesis and evaluation skills.

This paper illustrates the adaptation of Lu Xun 5-Reaches learning technique as activities in the teaching of Control System Design course and its measurement. It is hypothesised that this technique that has catapulted every Lu Xun learning into internalised knowledge could alleviate the threat and make learning Control System Design compelling and interesting. Section 2 discusses the teaching of Control System Design course, the Lu Xun 5-Reaches learning technique and activities designed to implement it. Section 3 presents and discusses statistics on the degree of reach from such activities and its implication.

\subsection{Methodology}

Even though there have been several curricular revisions to the Electrical Engineering programs, Control System Design remains a core course curriculum. It is currently a core course for Semester 5, Electronic Engineering Program, Faculty of Electrical Engineering, Universiti Teknologi MARA. The outcomes of Control System Design course include to enable students in (i) applying the fundamentals of Control System Theory course; (ii) designing compensator using Root Locus technique; (iii) designing compensator using Bode technique. In order to achieve the outcomes, the course is structured to first review and refresh the fundamental theories and concepts in Control System Theory course some semesters ago. Then, Root Locus technique is delivered before the Bode technique, with it being simpler. The approach used in the teaching of both technique is similar. First, the rules for sketching are explained and illustrated with the sketching of the uncompensated system. This is then ensued with the analysis of the uncompensated system to determine its present operating conditions and analyse the prescribed specifications. This step is required for the selection of compensator. Teaching on the compensator design is adopted using a simple-to-complex approach, starting with gain compensator, lag/PI compensator, lead/PD compensator and lead-lag/PID compensator. Performance evaluation of the compensator is incomplete without relating the frequency domain's performance, i.e. dominant pole, phase margin, bandwidth, to the time domain, i.e. settling time, peak time, per cent overshoot.

Learning with Lu Xun 5-Reaches engages our 5-organs, i.e. Heart, Eye, Mouth, Hand and Brain, which can be related to Gardner 5-sensory modalities, i.e. visual-spatial, verbal-linguistic, logical-mathematical, bodily-kinesthetic, intrapersonal and interpersonal (Gardner, 2011; Gardner, 1996; Gardner, 2011). Engagement of the Heart means focusing on energy and attention to learning through listening. Engagement of the Eye means sharp and meticulous observation in learning, while prolific in what to learn. Engagement of the Mouth means reading out or discussion, soft or loud, with compulsory auditory reception and emotional expression. This is said to fire the Eye and Ear's neural pathway, which can enhance the understanding and storage into permanent memory. Engagement of the Hand means diligently taking down notes, making annotation and book-marking. Engagement of the Brain means assiduously thinking and reflecting on what has been learnt, to become aware of the knowledge and internalised it (Wang, 1984; Kowallis 1996).

The following activities are concocted into the class's knowledge delivery process to engage the 5-organs of students while they are learning.

Table 1. Activities to Implement the Lu Xun 5-Reaches Learning Technique

\begin{tabular}{ll}
\hline & \multicolumn{1}{c}{ Activity } \\
\hline 1 & Use the handout to remind the student of date of quiz, assignment, test and examination \\
2 & Review Control Theory 1 by doing past year paper \\
3 & Highlight keywords/ key sentences in lecture notes \\
5 & Answer pop-up knowledge questions \\
6 & Learn controller design step by step, Root locus and Bode technique \\
7 & Solve controller design on Bode diagrams pre-prepared by the lecturer \\
8 & Work in a team to compete in recalling equations and solving the fundamental problem \\
9 & Work in a team to solve the controller design problem on whiteboard facilitated by the \\
& lecturer \\
10 & Analyze performance with each student after tests \\
\hline
\end{tabular}

\begin{tabular}{|c|c|c|c|c|c|c|}
\hline & Lu Xun 5-Reaches & Eye & Hand & Mouth & $\begin{array}{l}\text { Heart/ } \\
\text { Ear }\end{array}$ & Brain \\
\hline & $\begin{array}{l}\text { Reflect back when you were doing } \\
\text { Activity } 1-10 \text {, put a ' } Y \text { ' at the box of } \\
\text { organs you have used while } \\
\text { putting an ' } N \text { ' at the box you did not } \\
\text { use. }\end{array}$ & $\begin{array}{l}\text { See } \\
\text { Observe }\end{array}$ & Write & $\begin{array}{l}\text { Read } \\
\text { Discuss }\end{array}$ & $\begin{array}{l}\text { Listen } \\
\text { Focus }\end{array}$ & $\begin{array}{l}\text { Think } \\
\text { Reflect }\end{array}$ \\
\hline 1 & Activity 1 from Table 1 & & & & & \\
\hline 2 & Activity 2 from Table 1 and so on & & & & & \\
\hline
\end{tabular}




\subsection{Results and Discussions}

The questionnaires were distributed to students of Control System Design course at the last class of the course. Before filling up, the Lu Xun 5-Reaches for learning was first explained, and students were asked to reflect on the activities in Table 1 during their learning process. Fig.1 displays the per cent of the study population, engaging the organs in performing each activity. The study population consists of 128 students, from four semesters.

Activity 5 leads the students from basic sketch of Root locus and Bode to design, one example for each compensator type. However, the repetitive teaching of the basic sketch for each design is impractical time-wise and boring. In addition, the class can become difficult to control, when diligent students who have completed first have to wait for those who have not. Activity 6 bypasses this by providing the basic plots for students to focus on the design process. Instead, the students are given an inventory of basic plots to draw for all control design examples. Activity 7 enforces this with students having to mark their solutions against those provided by the lecturer and submitting their marks. Activity 8 prompts the reflection of materials learned, through competition between teams on recalling formulae (such as, write the formulae for natural frequency-dependent bandwidth); answering to knowledge-taxonomy question (such as, what is closed-loop control system); recalling the procedural steps in designing a controller (such as, describe steps in designing the lead-lag compensator) and so on. Activity 9 presents a control problem for students to solve in teams, by recalling procedure inactivity (5-7), facilitated by the lecturer. For example, in the lag-compensator design using Bode, they have to first analyse the problem into the specification for steady-state error and transient response. It is the students who are working, giving their solutions on the whiteboard and criticising each other. Everyone is on the move in the class, in total disorder, bustling with discussion and race against time.

For Activity 5-9, which is mathematics in nature and involves recalling equations, solving fundamental and controller design problem, more than $86 \%$ engaged the Eye, Hand and Brain, as shown in Fig. 1. (e-i). Since Activity 5, 8 and 9 are teamwork, where intra and inter-team discussion and listening are necessary, engagement with the Mouth and Heart is higher than that for Activity 6 and 7 , which is self-practice.

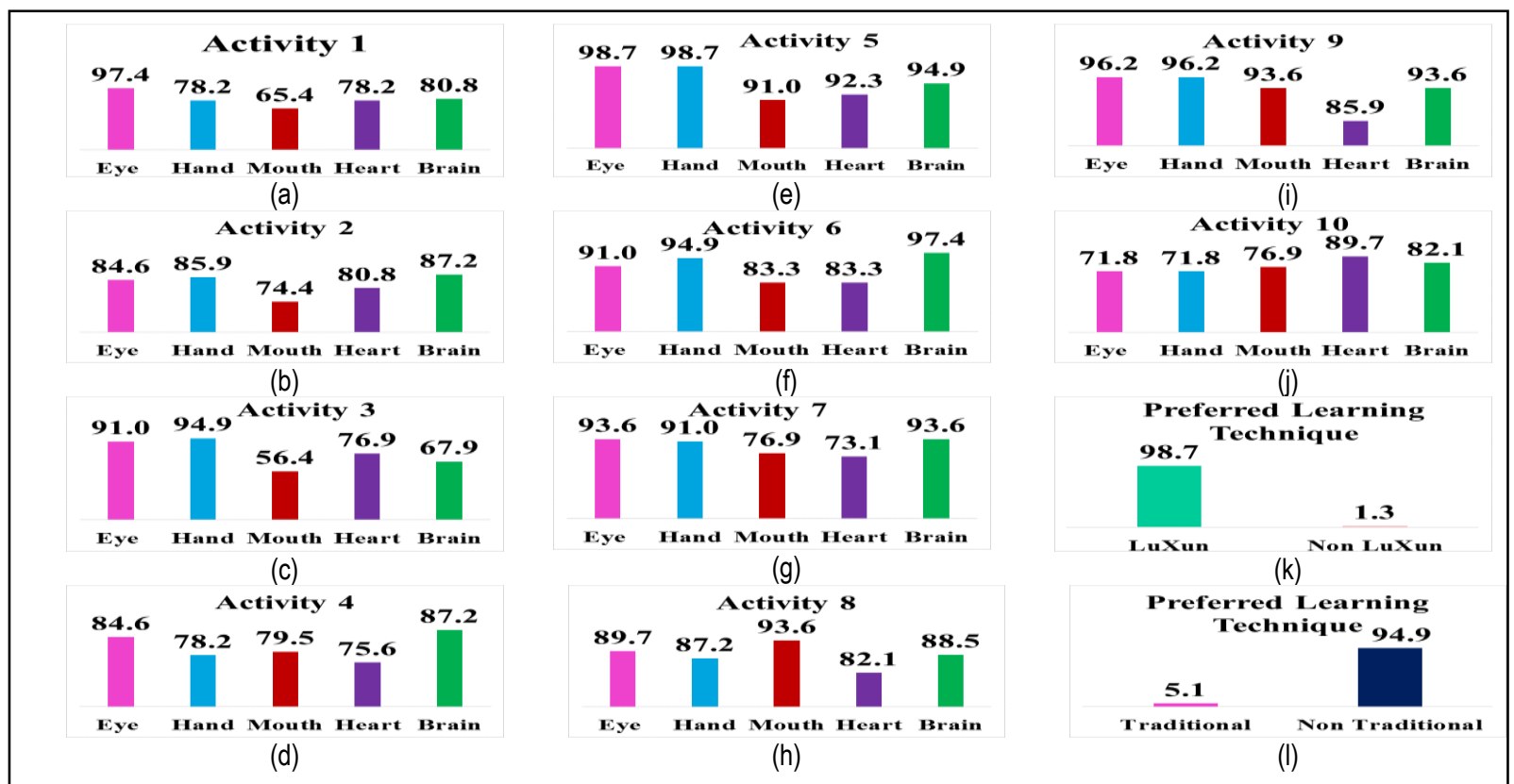

Fig.1 (a)-(j): Degree of Reach (\%) for 5-organs in response to Activity 1-10; Fig.1 (k)-(I): Degree of Preference (\%) for Lu Xun 5-Reaches and Traditional learning technique

Activity 2 dictates students to review the fundamentals of Control System Theory, which they have studied during Semester 3 or Diploma program. The review is by working through one past examination paper, limited to topics indispensable to this course, such as open-loop/ closed-loop transfer function, Routh Hurwitz criterion, steady-state and transient response analysis. Being self-practice, the number of participants is lower than Activity 5-9, as in Fig. 1. (b). However, of those participated, the organs of reach are similar to Activity $5-9$, since this activity is also mathematical.

Students in this course are provided with course notes (Khuan Y Lee et al.). They would assume they have all they need and play truant. Contrary to this, Activity 3 makes them highlight important points and keywords; colour to differentiate between graph; annotate important pages for revision, etc., in class. In addition, the course notes are deliberately embedded with common mistakes made by their predecessors. Activity 4 shows pop-up prompting questions to discover these mistakes. For example, students are most likely to use the multiply-operand, instead of the division-operand, to improve steady-state error. Fig. 1. (c) shows Activity 3 is unable to draw discussion from students, hence observing the least engaged with Mouth, but a high degree of reach for Eye and Hand. Activity 4 , being inquisitive based, shows a higher engagement of Mouth and Brain than Activity 3, as in Fig. 1. (d). 
Activity 1 is intended to help students come into the class with focus and attention to do well. Fig. 1. (a) shows $97.4 \%$ of the students engaged their Eye and more than $80 \%$ for Hand, Heart and Brain, showing fully attentive towards the deadline for the quiz, assignment, test and examination.

Fig. 1. (j) displays Activity 10 having the least engagement with Eyes and Hand. This is because the activity entails analysing individual performance with students, which necessitates minimal seeing and writing. However, it is interesting to find that $82 \%$ or more are listening to and thinking about the analysis and recommendation.

From Fig. 1. (k-I), it is encouraging to observe that $99 \%$ of the study population would observe the Lu Xun 5-Reaches learning technique if they were to follow a career path in teaching, from this exposure, while $95 \%$ decide against to practice the traditional approach, which is mainly spoon-fed and non-interactive.

In another aspect, the average statistics from this survey is discovered to associate with student reception of these activities. Being quantitative, this can provide an objective feedback indicator for improvement in content design and delivery. About Fig. 2. (a), of all the activities, on an average, Eye records the highest degree of reach (90\%) while Mouth the lowest $(79 \%)$. Though satisfactory, activities that encourage students to query can be increased. Fig. 2. (b) displays the average degree of reach by the five organs for each activity. Relative to other activities on the list, Activity 5-9 are found to be the most capable of engaging the use of the five organs (more than $86 \%$ ), while Activity 3 and 10 the least capable (less than $80 \%$ ). This proposes the former is more receptive to the students while the latter is less. Of these, Activity 5 records the highest engagement of all five organs.

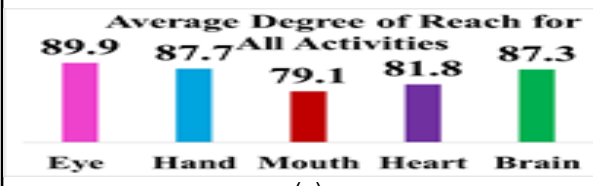

(a)

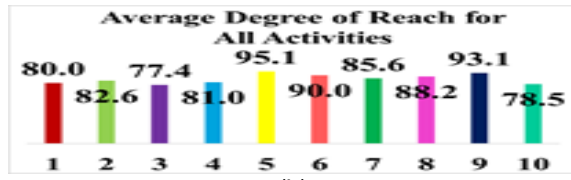

(b)

Fig. 2. (a) Average Degree of Reach (\%) for the five organs for all activities; (b) Average Degree of Reach (\%) for the five organs in response to Activity 1-10.

In his theoretical model of Multiple Intelligence, Gardner articulates eight modalities for a behaviour to be considered "Intelligence", i.e. visual-spatial, verbal-linguistic, logical-mathematical, bodily-kinesthetic, interpersonal, intrapersonal, musical-rhythmic and naturalistic (Gardner, 2011). Except for the last two modalities, the rest are sensory-related to the Lu Xun learning technique's five organs. This implies that Lu Xun 5-Reaches learning technique is related to the development of this "Intelligence". And this has been designed into Control System Design course through activities, which shows a reasonable degree of reaches to the five organs from the measurement.

In hindsight, there exist side benefits from the activities. Activity 3 teaches them to locate key points as they are learning. Activity 4 trains them to be curious with whatever they are learning. Activity 5-7 teaches them about being prepared for tasks, with the use of web resources. Activity 8-9 encourages teamwork, friendship and fun, besides developing the skill for analysis, synthesis and evaluation.

\subsection{Conclusions}

This paper illustrates how the Lu Xun 5-Reaches learning technique is implemented in the Control System Design course teaching through activities and its measurement. This is the first time that the content design and delivery of Control System Design course are examined with respect to the engagement of the five organs in an objective manner. On an average, Activity 5-9 is found to be the most capable of engaging students in using the five organs, while Eye, Hand and Brain the most engaging organs in learning Control System Design course. Deriving from this, activities engaging Mouth and Heart need to be enhanced. With the 5-Reaches through the spontaneous and interactive delivery method, the direct benefits are concentrated learning, sharp observation, enhanced permanent memory, organised memory storage and internalisation of knowledge. The side benefits include independent learning, organised knowledge, curiosity, networking and having fun. It is also interesting to note that the Lu Xun 5-Reaches learning technique promotes the development of modalities that reflect Intelligence in Gardner's multiple intelligence model.

\section{Acknowledgements}

The author would like to thank the Research Management Institute, Universiti Teknologi MARA, Malaysia, for grant 600-RMI/DANA 5/3/ARAS (14/2015) and the Faculty of Electrical Engineering, Universiti Teknologi MARA, Malaysia, for the support and assistance given to the authors in carrying out this research.

\section{References}

Gardner, H. (2011). Frames of mind: The theory of multiple intelligences. Basic Books, 3rd edition. 
Lee, K.Y., CSSR2018, 5th International Conference on Science and Social Research, Le Meridien Kota Kinabalu Hotel, 5 - 6 Dec 2018, E-BPJ, 5(SI3), Dec 2020 (pp.167-171)

Gardner, H. (1996). More deeply into the theory of multiple intelligences. NASSP Bulletin 9, 80(583), 1-7.

Gardner, H. (2011). Changing Minds: How the application of the multiple intelligences (MI) framework could positively contribute to international negotiation theory and practice. Psychological and Political Strategies for Peace Negotiation: A Cognitive Approach, 1-14.

Kowallis, J. (1996). Interpreting Lu Xun. Chinese Literature: Essays, Articles, Review,18: 153-164.

Khuan Y Lee., Radzol, A. R. M., Alias, N. M. A. and Thamrin, N. M. (in submission for publication). Companion book for Control System Design. UiTM Press, Universiti Teknologi MARA.

Li, Yong Nin. (2014). Li Ka Shing: no accidental success. China Overseas Press.

Wang, Shiqing., (1984). Lu Xun: A Biography. Foreign Languages Press, $1^{\text {st }}$ edition. 